\title{
Egypt Family Planning Method Mix Indicates Shifting toward Hormonal Contraceptives
}

\author{
Ghada Wahby, Hend Sabry, Madiha Abdel-Razik, Marwa Rashad Salem*, Fayrouz EL Aguizy \\ Department of Public Health and Community Medicine, Faculty of Medicine, Cairo University, Cairo, Egypt
}



\section{Introduction}

There is evidence that Sustainable Development Goals (SDGs) will not be achieved unless, and there is universal access to quality reproductive health services [1], [2]. Therefore, new target has been added to SDGs that emphasizes the importance of family planning (FP), increasing contraceptive prevalence rate $(C P R)$, reducing unmet needs for $F P$ (UNFP) and discontinuation rate (DR), and proper FP method-mix to support reducing maternal morbidity and mortality [3], [4].

According to Egypt Demographic and Health Survey (EDHS) 2014, the public sector was the source of FP methods for $56.7 \%$ of all FP methods users; $62.9 \%$ of intrauterine device (IUD) users, $34.4 \%$ of oral contraceptives (OCs) users, and $83.1 \%$ of injectables users [5]. EDHS 2005 showed that CPR was $56.5 \%$ with IUD $61.5 \%$, OCs $16.7 \%$, and injectables $11.9 \%$ [6]. In EDHS 2014, CPR was 56.9\% with IUD 51.4\%, OCs $27.4 \%$, and injectables $14.5 \%$. According to the Ministry of Health and Population (MOHP)/FP program statistics 2015 , FP method mix profile (the profile of the relative level of use of different contraceptive methods) among
MOHP clients was $54 \%$ for OCs, $37 \%$ for injectables and $7 \%$ for IUD 9 [7]. Similar findings were provided by studies in other countries [8], [9].

Senegal study, 2015 showed DR as follows: Implants had the lowest 1-year DRs (6.3\%) followed by the IUD (18.4\%) while higher rates were seen for daily pills (38\%), injectables (32.7\%) [8].

The shift from IUD as an effective long-term, one-decision, lowest DR FP method compared to OCs that have highest DR could have negative impact on FP Program [10], [11]. In addition, the use of combined estrogen-progestin OCs could interfere with lactation with subsequent increased risk of child morbidity. High DR of OCs could lead to unintended pregnancy with increased risk of poor maternal health [12], [13].

The change in FP method mix profile across time indicates changes in demand for FP method as availability, accessibility, effectiveness, safety, and/or acceptability (cultural, social, religious, or economic) and/or supply of FP methods (policies/ regulations, availability of quality FP methods, accessibility of quality services, availability of service providers (SP), training, logistic management, time management/clients, supervision, incentive system, 
family medicine model approach, and/or integrated services) [14], [15], [16].

The study conducted by El-Zanaty and Associates [17] and Abdel-Razik et al. [18] provided evidence that FP program in its transition phase from vertical to integrated program has reported shortage in FP program specific activities as clinical supervision and on-job training [17], [18].

Identifying factors influencing the profile of method mix is crucial for adjustment of the FP services policies an $d$ regulations that ensure the use of effective and safe methods and considering the cultural background of Egyptian women.

\section{Policy and practical implications of the study}

The study is of practical importance for policy makers and FP program managers as the profile of FP method-mix with a shift from a mechanical method as IUD to hormonal methods such as OCs and injectables predicts a critical situation for maternal and child health and reflects shortcomings in FP service delivery program. Thus, the objective of this study is to identify reasons behind the change in the FP method mix profile (the shift from IUD to OCs use) among MOHP/FP clients considering demand and supply components.

\section{Methods}

\section{Study setting}

$\mathrm{MOHP} / \mathrm{HQ}$, five governorates included in MOHP/UNFPA-Contraceptive Security Project (CSP) and presenting geographic regions of Egypt: Urban governorates (Cairo), Lower Egypt (Sharkia and Menofia), and Upper Egypt (Fayoum and Beni-Suef).

\section{Study design}

Health system-operations research, exploratory study conducted at four levels of MOHP- FP service delivery: Central (HQ), Governorate, District and service delivery points.

\section{Sample size and sampling technique}

Five selected governorates showed increase in FP clients OCs users and decrease in IUD users as derived from MOHP service statistics [7] (Table 1).

All districts' FP directors and nurse supervisors were included in the sample. Available physicians and nurses were included in the study (Table 2).
Table 1: Percent of MOHP- FP clients 2007 versus 2011 according to OCs and IUD use (MIS-MOHP/FP) for five CSP governorates

\begin{tabular}{|c|c|c|c|}
\hline $\begin{array}{l}2007 \text { Vs. } 2011 \\
\text { Governorates }\end{array}$ & $\begin{array}{l}\text { \% increase in } \\
\text { total FP clients }\end{array}$ & $\begin{array}{l}\% \text { increase in } \\
\text { OCs users }\end{array}$ & $\%$ decrease in IUD users \\
\hline Sharkia & $80 \%$ & $26 \%$ & $-7 \%$ \\
\hline Menofia & $49 \%$ & $17 \%$ & $-8 \%$ \\
\hline Cairo & $6 \%$ & $9 \%$ & $-7 \%$ \\
\hline Beni-Suef & $34 \%$ & $10 \%$ & $-6 \%$ \\
\hline Fayoum & $31 \%$ & $11 \%$ & $-7 \%$ \\
\hline
\end{tabular}

\section{Data collection}

Quantitative data

The sources of the quantitative data were selfadministered questionnaire form to a sample of 600 respondents. The form included inquiries about:

1. The changing attitude of clients toward FP methods

2. Changes in FP method supply and management of resources regarding policies, regulations, incentives, supervision, and training

3. The questionnaire included statements related to influential power (IP) that contributed to shift from IUD to OCs use by FP clients. The acceptability to specific statements related to SPs, policies and managerial methods are recorded in the form completed by respondents.

Table 2: Sample size and characteristics of respondents distributed according to governorates included in the sample

\begin{tabular}{llllll}
\hline Governorates & District directors & Nurse supervisors & Physicians & Nurses & Total \\
\hline Cairo & 23 & 23 & 30 & 30 & 106 \\
Fayoum & 7 & 7 & 40 & 40 & 94 \\
Beni-Suef & 7 & 7 & 40 & 40 & 94 \\
Sharkia & 13 & 13 & 65 & 65 & 156 \\
Menofia & 10 & 10 & 65 & 65 & 150 \\
Total & 60 & 60 & 240 & 240 & 600 \\
\hline
\end{tabular}

\section{Qualitative data}

In-depth interview with $\mathrm{MOHP} / \mathrm{HQ}$ staff members and one focus group discussions (FGDs) with MOHP/FP directors and another one with nurse supervisors in the five governorates.

Qualitative data presented as views of staff members at central and governorate level were used to provide explanation and interpretation to the quantitative data regarding the demand and supply sides. Before each FGD, the investigator facilitated the discussion by introducing all participants, explaining the broad subjects of discussion, and encouraging everyone to express their thoughts. Following each FGD, the reviewed recorded scripts are typed.

\section{Definition of variables and indicators}

- IP of SPs for OCs use: The percent of respondents accepted the statement that, physicians versus nurses versus community workers (CW) accepted the statement that refer to category of SPs who influence clients toward shift to OCs use 
IP of resources management for OCs use: The percent of respondents accepted the statement that point to the role of MOHP six operational policies as influential factors for FP method shift to OCs. Those operational policies included: Incentives for IUD insertion, Family Medicine, Training of SPs in IUD, insertion, FP method supply/logistic management, central teams' supervision, and district teams' supervision IP of clients' acceptability for OCs use: The percent of respondents accepted the Statements related to reasons that make FP clients prefer using OCs than other FP methods: Availability of OCs all times in MOHP clinics, no need for gynecological examination, no side effects, reasonable price and the user has control over OCs' use

- IP for shifting from IUD to other contraceptive methods: The percent of respondents accepted the six statements related to reasons of shifting from IUD to other contraceptive methods: Unsatisfactory training of physicians in IUD insertion, improper response of physicians to manage side effects of the IUD, to incentives to SPs in case of IUD insertion, the need for follow-up of IUD users, IUD insertion consume much of physician's time and IUD insertion is linked with non-response to clients' rights.

\section{Data analysis plan}

The analysis covered two major components: Demand and supply of FP methods to identify significant responses across the groups of respondents.

\section{Data quality check}

Completed self-administered questionnaire formats had been office- reviewed and further revision during data entry and preliminary analysis.

\section{Quantitative data}

Data entry was carried out using Statistical Package for Social Science (SPSS) version 24.0 (IBM, SPSS, USA). Categorical variables were expressed in percentages; Chi-square was used and applied. $p<0.05$ was considered significant.

\section{interview}

\section{Qualitative data: FGDs and in-depth}

We based data processing on the thematic content analysis technique, which aims to get descriptions of the message content using a systematic and objective procedure. The analysis was carried out independently by two authors M.R and M.S. They read the transcript multiple times, condensed, made meaningful statements, and devised themes and subthemes.

\section{Ethical approval}

There was an approval by the MOHP/FP Technical Committee to conduct the study, approved the proposal, questionnaire form and in-depth and FGD guidelines. Qualitative data are collected after getting informed consent from participants. The questionnaire form was anonymous, and informed consent was obtained from participants as instructions in the form.

\section{Results}

Quantitative data included a total of 607 respondents where $(94 \%)$ affirmed their observation of proportionate increase in OCs clients over time. Table 3 illustrates responses of respondents toward acceptability to statement about role of SPs as an influential factor contributing to FP method shift toward OCs. The IP of physicians to incline clients to use OCs was accepted by $35 \%$ of respondents, versus $(22 \%)$ for nurses and $(28 \%)$ for CWs. IP of physicians to motivate toward OCs use was the highest $(72 \%)$ in Fayoum Governorate $(p=0.00)$. IP for nurses was $(41 \%)$ in Fayoum $(p=0.002)$ and IP of $\mathrm{CW}$ was the highest in Beni-Suef governorate (38\%) $(p=0.00)$.

Table 4 demonstrates factors contributing to FP method shift toward OCs related to elements of MOHP operational policies and management of resources. Incentive system had (50\%) IP followed by training system (IP=39\%). There were statistically significant differences across governorates in the six management elements. Beni-Suef Governorate reported highest IP of incentive system (68\%), and IP of FP method supply $(75 \%)$.

Table 3: Influential power for FP method shift toward OCs: Service providers and outreach workers by governorates

\begin{tabular}{|c|c|c|c|c|c|c|c|c|}
\hline \multirow[t]{2}{*}{ Service providers } & \multirow[t]{2}{*}{ Acceptability of statement by respondents } & \multicolumn{7}{|c|}{ Governorates } \\
\hline & & Cairo & Fayoum & Menofia & Beni-Suef & Sharkia & Total & $\mathrm{p}$ \\
\hline \multirow[t]{2}{*}{ Physicians } & Influential power & $29 \%$ & $72 \%$ & $28 \%$ & $40 \%$ & $32 \%$ & $35 \%$ & 0.00 \\
\hline & Total respondents & 92 & 29 & 106 & 95 & 149 & 471 & \\
\hline \multirow[t]{2}{*}{ Nurses } & Influential power & $16 \%$ & $41 \%$ & $25 \%$ & $29 \%$ & $18 \%$ & $22 \%$ & 0.002 \\
\hline & Total respondents & 92 & 21 & 105 & 93 & 148 & 459 & \\
\hline \multirow[t]{2}{*}{ Community workers } & Influential power & $12 \%$ & $37 \%$ & $35 \%$ & $38 \%$ & $25 \%$ & $28 \%$ & 0.00 \\
\hline & Total respondents & 91 & 19 & 108 & 94 & 149 & 461 & \\
\hline
\end{tabular}


Table 5 presents respondents' acceptability to the statements related to clients' reasons to prefer use of OCs across Governorates. The statement that "the user has control over OCs use" was acceptable by $79 \%$ of respondents. Reasonable price of OCs had IP of $68 \%$ followed by "reasonable price" IP $(75 \%)$ followed by, availability all the time in MOHP clinics IP (68\%) and "no need for gynecological examination in case of using OCs" (IP = 66\%). There was an insignificant difference across governorates regarding specific reason of clients' preference to OCs, which is "no need for gynecological examination" $(p=0.21)$. There were statistically significant variations $(p=0.00)$ across governorates for other four reasons for clients' preference to use OCs. Beni-Suef governorate respondents attributed preference of clients to OCs use due to: Availability of OC in MOHP clinics all the times (IP = 95\%) and reasonable price $(I P=90 \%)$ and less side effects (IP $=57 \%)$. Sharkia governorate respondents delineated that clients inclination toward OCs use is due to "the user has control over OCs use (87\%).

Table 6 indicates consensus among respondents in different FP jobs $(p>0.05)$ regarding the factors related to, "user has control over OCs use" (IP $=79 \%)$, availability of OCs all times in MOHP clinics (IP $=68 \%)$, and accessibility to OCs without gynecological examination (IP $=68 \%$ ). However, there were statistically significant differences across categories of respondents regarding clients' preference toward OCs due to limited side effects (IP $=42 \%$ for nurses) $(p=0.01)$ and reasonable price (IP $=79 \%)$ as confirmed by nurses $(p=0.03)$.

Figure 1 highlights rank order of IP for causes of shift from IUD use to OCs as expressed by respondents. No incentives for IUD insertion services were priority reason (IP $=64 \%$ ), and IUD use needs follow-up services (51\%).

Table 7 clarifies presence of statistically significant differences across governorates regarding the six determinants for FP clients shift from IUD to OCs use $(p=0.00)$. Respondents from Beni-Suef governorate demonstrated highest IP for shifting from IUD to OCs use: No incentives for IUD insertion services (IP = 74\%), ineffective training of physicians (IP=67\%), IUD use needs follow-up services (IP $=62 \%)$, improper response of physicians to side effects (IP $=58 \%$ ), and IUD insertion is linked with non-response to clients' rights (IP $=47 \%$ ).

Table 8 shows the statistically significant differences between perspectives of respondents in different jobs regarding three determinants for shift from IUD to OCs use. FP nurse supervisors $(77 \%)$ and FP

Table 4: Influential power for FP method shift toward OCs: FP operational policies and regulations and management of resources by governorates

\begin{tabular}{|c|c|c|c|c|c|c|c|c|}
\hline \multirow[t]{2}{*}{ MOHP operational policies } & \multirow[t]{2}{*}{ Acceptability } & \multicolumn{7}{|c|}{ Governorates } \\
\hline & & Cairo & Fayoum & Menofia & Beni-Suef & Sharkia & Total & $p$ \\
\hline \multirow{2}{*}{ Incentive system } & Influential power & $49 \%$ & $21 \%$ & $34 \%$ & $64 \%$ & $57 \%$ & $50 \%$ & 0.00 \\
\hline & Total respondents & 92 & 14 & 120 & 97 & 148 & 471 & \\
\hline \multirow[t]{2}{*}{ Family medicine system } & Influential power & $22 \%$ & $18 \%$ & $23 \%$ & $32 \%$ & $13 \%$ & $22 \%$ & 0.002 \\
\hline & Total respondents & 92 & 15 & 102 & 97 & 145 & 451 & \\
\hline \multirow[t]{2}{*}{ Family planning method supply } & Influential power & $8 \%$ & $31 \%$ & $18 \%$ & $68 \%$ & $8 \%$ & $24 \%$ & 0.00 \\
\hline & Total respondents & 92 & 15 & 102 & 97 & 145 & 451 & \\
\hline \multirow{2}{*}{ Training system } & Influential power & $26 \%$ & $42 \%$ & $44 \%$ & $48 \%$ & $38 \%$ & $39 \%$ & 0.02 \\
\hline & Total respondents & 91 & 16 & 111 & 96 & 150 & 464 & \\
\hline \multirow[t]{2}{*}{ Central supervision } & Influential power & $3 \%$ & $9 \%$ & $17 \%$ & $5 \%$ & $1 \%$ & $6 \%$ & 0.00 \\
\hline & Total respondents & 92 & 15 & 102 & 97 & 150 & 456 & \\
\hline \multirow[t]{2}{*}{ Local supervision } & Influential power & $2 \%$ & $4 \%$ & $11 \%$ & $6 \%$ & $1 \%$ & $5 \%$ & 0.00 \\
\hline & Total respondents & 92 & 15 & 100 & 91 & 150 & 448 & \\
\hline
\end{tabular}

Table 5: Influential power for clients' choice for OCs as expressed by the respondents by governorates

\begin{tabular}{|c|c|c|c|c|c|c|c|c|}
\hline \multirow[t]{2}{*}{ Reasons for clients' choice of OCs } & \multirow[t]{2}{*}{ Acceptability } & \multicolumn{7}{|c|}{ Governorates } \\
\hline & & Cairo & Fayoum & Menofia & Beni-Suef & Sharkia & Total & $\mathrm{p}$ \\
\hline \multirow[t]{2}{*}{ Availability all the times in MOHP clinics } & Influential power & $55 \%$ & $74 \%$ & $69 \%$ & $90 \%$ & $58 \%$ & $68 \%$ & 0.00 \\
\hline & Total respondents & 96 & 93 & 125 & 96 & 150 & 560 & \\
\hline \multirow[t]{2}{*}{ No need for gynecological examination } & Influential power & $68 \%$ & $65 \%$ & $63 \%$ & $66 \%$ & $70 \%$ & $66 \%$ & 0.21 \\
\hline & Total respondents & 97 & 94 & 131 & 99 & 151 & 572 & \\
\hline \multirow[t]{2}{*}{ No side effects } & Influential power & $38 \%$ & $18 \%$ & $36 \%$ & $57 \%$ & $33 \%$ & $36 \%$ & 0.00 \\
\hline & Total respondents & 92 & 85 & 112 & 97 & 148 & 534 & \\
\hline \multirow{2}{*}{ Reasonable price } & Influential power & $74 \%$ & $71 \%$ & $72 \%$ & $85 \%$ & $74 \%$ & $75 \%$ & 0.00 \\
\hline & Total respondents & 97 & 92 & 120 & 97 & 148 & 554 & \\
\hline \multirow[t]{2}{*}{ The user has control over OCs use } & Influential power & $77 \%$ & $77 \%$ & $76 \%$ & $73 \%$ & $87 \%$ & $79 \%$ & 0.00 \\
\hline & Total respondents & 97 & 88 & 136 & 92 & 149 & 562 & \\
\hline
\end{tabular}

Table 6: Influential power for clients' choice for OCs as expressed by the respondents according to their current job

\begin{tabular}{|c|c|c|c|c|c|c|c|c|}
\hline \multirow[t]{2}{*}{ Advantages of OCs } & \multirow[t]{2}{*}{ Acceptability } & \multicolumn{7}{|c|}{ Current Job of the respondents } \\
\hline & & FPDD & FPDNS & Male physician & Female physician & FP nurse & Total & $\mathrm{p}$ \\
\hline \multirow[t]{2}{*}{ Availability all the times in MOHP clinics } & Influential power & $59 \%$ & $67 \%$ & $77 \%$ & $66 \%$ & $70 \%$ & $68 \%$ & 0.13 \\
\hline & Total respondents & 55 & 57 & 70 & 139 & 203 & 524 & \\
\hline \multirow[t]{2}{*}{ Accessible without Gyn. Examination } & Influential power I & $72 \%$ & $75 \%$ & $67 \%$ & $64 \%$ & $67 \%$ & $68 \%$ & 0.14 \\
\hline & Total respondents & 57 & 62 & 69 & 147 & 204 & 539 & \\
\hline \multirow[t]{2}{*}{ No Side Effects } & Influential power & $39 \%$ & $39 \%$ & $35 \%$ & $28 \%$ & $42 \%$ & $36 \%$ & 0.01 \\
\hline & Total respondents & 53 & 59 & 68 & 136 & 187 & 503 & \\
\hline \multirow[t]{2}{*}{ Reasonable price } & Influential power & $74 \%$ & $75 \%$ & $77 \%$ & $69 \%$ & $79 \%$ & $75 \%$ & 0.03 \\
\hline & Total respondents & 55 & 59 & 69 & 138 & 198 & 519 & \\
\hline \multirow[t]{2}{*}{ The user has control over OCs use } & Influential power & $82 \%$ & $80 \%$ & $74 \%$ & $80 \%$ & $79 \%$ & $79 \%$ & 0.13 \\
\hline & Total respondents & 57 & 59 & 69 & 141 & 202 & 528 & \\
\hline
\end{tabular}


district directors $(76 \%)$ emphasized role of incentives for IUD insertion services. Nurses attributed the shift from IUD to OCs to the need for follow-up services for IUD users (IP $=56 \%)$.

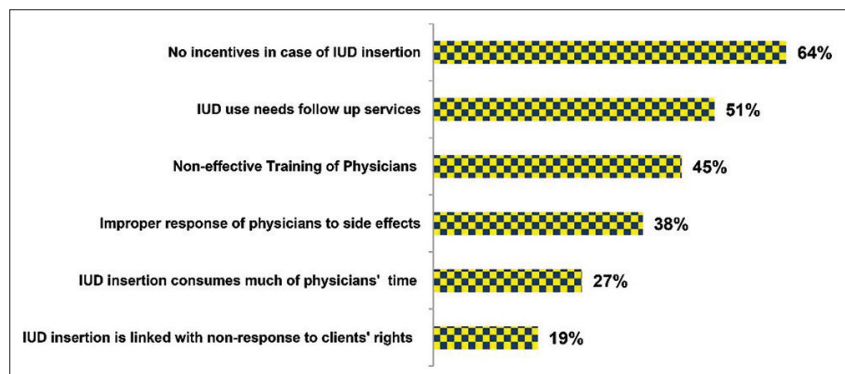

Figure 1: Percent of responses of Family Planning service providers according to reasons for shift from IUD use to other methods

Inquiries about acceptability of respondents to involve nurses to provide IUD insertion services, showed that $65 \%$ did not accept this policy, $21 \%$ accepted, and $14 \%$ highly accepted this policy. Table 9 showed that in case of accepting policy of adding services of IUD insertion to nurses' job, selection criteria will be training nurses worked in FP for more than 5 years as expressed by nurses (IP $=65 \%$ ) and to have specialized nurses for IUD insertion (IP = 44\%).

\section{Qualitative data}

Themes.

Public - private partnership.

The transcripts of the interviews displayed the following themes as stated by study participants.

\section{method mix \\ Current situation of family planning}

FP program managers affirmed the shift from IUD to OCs use, after withdrawal of USAID donations and technical assistance to Egypt FP program

Almost of participants from MOHP - FP sector $\mathrm{HQ}$ and $\mathrm{FP}$ directors at governorate levels affirmed the observation that during the last 10 years, there was progressive increase in proportion of OCs clients. The previous pattern of method mix with predominance of IUD is attributed to donor support program (1977-2005) where IUD was supplied through USAID. Technical assistance, training and supervision of SPs were included under the umbrella of USAID projects after phasing out of donor support and shortage in trained FP SPs as well as constructive supervision.

The success of Egypt pharmaceutical companies in mass production of OCs

Having OCs available through Egypt pharmaceutical companies could facilitate supply OCs through public and private sectors without seeking medical counseling in FP clinics. This issue could have a negative outcome on FP program in the community and reduce Contraceptive Coverage Rate (CCR) (i.e., Percent of contraceptive methods dispensed from MOHP facilities expressed as Couple Year Protection per all married women in a certain period of time and locality).

MOHP/FP staff members referred the observation of shift from IUD to OCs use to governorates' requests for progressive increase in the amount of Microcept pills production by Egypt pharmaceutical companies. MOHP staff in governorates highlighted issue of true increase in the proportion of OCs clients in MOHP/FP clinics as recorded in service statistics. However, MOHP governorate staff considered that the indicator measuring their performance is CCR rather than method-mix. The increase of combined OCs use has shortcomings related to hormonal contraceptive use and women's and children's health, especially using combined OCs by lactating women. The use of combined OCs keeps using under control of women with increase probability of discontinuation and increases the unwanted pregnancy and its subsequent misbehavior as unsafe abortion.

\section{Clients' choice to OCs is pivotal for formulating pattern of shift from one method to another}

FP District Directors-Sharkia governorate raised the issue of improvement in quality of client's usage of OCs on-daily bases. The participants described situation in MOHP/FP clinics that constitute a driving force for women to shift toward OCs.

Table 7: Influential power for shift from IUD to OCs expressed by respondents from different governorates

\begin{tabular}{|c|c|c|c|c|c|c|c|c|}
\hline \multirow[t]{2}{*}{ Causes of shift from IUD to OCs } & \multirow[t]{2}{*}{ Acceptability } & \multicolumn{7}{|c|}{ Governorates } \\
\hline & & Cairo & Fayoum & Menofia & Beni-Suef & Sharkia & Total & $\mathrm{p}$ \\
\hline \multirow[t]{2}{*}{ Non-effective Training of Physicians } & Influential power & $27 \%$ & $42 \%$ & $45 \%$ & $67 \%$ & $43 \%$ & $45 \%$ & 0.00 \\
\hline & Total respondents & 93 & 88 & 141 & 96 & 150 & 568 & \\
\hline \multirow[t]{2}{*}{ Improper response of physicians to side effects } & Influential power & $22 \%$ & $37 \%$ & $38 \%$ & $58 \%$ & $37 \%$ & $38 \%$ & 0.00 \\
\hline & Total respondents & 94 & 86 & 120 & 93 & 149 & 542 & \\
\hline \multirow[t]{2}{*}{ No incentives in case of IUD insertion } & Influential power & $60 \%$ & $68 \%$ & $49 \%$ & $74 \%$ & $71 \%$ & $64 \%$ & 0.00 \\
\hline & Total respondents & 96 & 89 & 137 & 91 & 147 & 560 & \\
\hline \multirow[t]{2}{*}{ IUD use needs follow-up services } & Influential power & $50 \%$ & $59 \%$ & $47 \%$ & $62 \%$ & $44 \%$ & $51 \%$ & 0.00 \\
\hline & Total respondents & 96 & 92 & 116 & 92 & 149 & 545 & \\
\hline \multirow[t]{2}{*}{ IUD insertion consumes much of physicians' time } & Influential power & $22 \%$ & $45 \%$ & $18 \%$ & $39 \%$ & $20 \%$ & $27 \%$ & 0.00 \\
\hline & Total respondents & 89 & 86 & 114 & 89 & 145 & 523 & \\
\hline \multirow[t]{2}{*}{ IUD insertion is linked with non-response to clients' rights } & Influential power & $11 \%$ & $17 \%$ & $12 \%$ & $47 \%$ & $15 \%$ & $19 \%$ & 0.00 \\
\hline & Total respondents & 89 & 86 & 114 & 89 & 145 & 523 & \\
\hline
\end{tabular}


Table 8: Influential power for shift from IUD to OCs according to current Job of respondents

\begin{tabular}{|c|c|c|c|c|c|c|c|c|}
\hline \multirow[t]{2}{*}{ Causes of shift from IUD to OCs } & \multirow[t]{2}{*}{ Acceptability } & \multicolumn{7}{|c|}{ Current job of the respondents } \\
\hline & & FPDD & FPDNS & Male physician & Female physician & FP nurse & Total & $\mathrm{p}$ \\
\hline \multirow[t]{2}{*}{ Non-effective training of physicians } & Influential power & $49 \%$ & $49 \%$ & $43 \%$ & $45 \%$ & $47 \%$ & $47 \%$ & 0.23 \\
\hline & Total respondents & 56 & 58 & 69 & 145 & 205 & 533 & \\
\hline \multirow[t]{2}{*}{ Improper response of physicians to side effects } & Influential power & $41 \%$ & $41 \%$ & $37 \%$ & $40 \%$ & $39 \%$ & $40 \%$ & 0.007 \\
\hline & Total respondents & 55 & 57 & 68 & 137 & 191 & 508 & \\
\hline \multirow[t]{2}{*}{ No incentives in case of IUD insertion } & Influential power & $76 \%$ & $77 \%$ & $66 \%$ & $62 \%$ & $61 \%$ & $65 \%$ & 0.017 \\
\hline & Total respondents & 56 & 62 & 68 & 142 & 199 & 527 & \\
\hline \multirow[t]{2}{*}{ IUD use needs follow-up services } & Influential power & $48 \%$ & $39 \%$ & $53 \%$ & $51 \%$ & $56 \%$ & $51 \%$ & 0.002 \\
\hline & Total respondents & 54 & 57 & 70 & 135 & 195 & 511 & \\
\hline \multirow[t]{2}{*}{ IUD insertion consumes much of physicians' time } & Influential power & $30 \%$ & $33 \%$ & $24 \%$ & $26 \%$ & $27 \%$ & $28 \%$ & 0.39 \\
\hline & Total respondents & 53 & 56 & 66 & 130 & 188 & 493 & \\
\hline \multirow[t]{2}{*}{ IUD insertion is linked with non-response to clients' rights } & Influential power & $11 \%$ & $18 \%$ & $21 \%$ & $20 \%$ & $23 \%$ & $20 \%$ & 0.13 \\
\hline & Total respondents & 53 & 57 & 64 & 134 & 185 & 493 & \\
\hline
\end{tabular}

\section{Family planning challenges}

SPs' performance was influenced by work climate created by foreign donations

Throughout the period of foreign donor supported FP projects, physicians and nurses were fascinated to work in FP program. The surplus of resources and legislations to get incentives from the fund raised from dispensed contraceptive methods were motivating for SPs to work in FP services especially IUD insertion services. In addition, well-designed practical training in FP was very attractive for new generations of physicians. Currently and after phasing out of foreign donation support, and cancelling the incentive legislation and decreased quality of training, physicians became no more interested to work in FP especially IUD insertion. Therefore, the physicians have the sense of unsatisfactory skills in IUD insertion. Physicians become no more interested to upgrade their performance in IUD insertion and to carry the risk of IUD insertion, while there is an alternative way to provide FP service through dispensing OCs. This situation had made MOHP/FP clinics work as pharmacies for dispensing OCs, rather than providing quality FP services that is based on proper counseling and discussing the cafeteria of FP methods to clients, to build up the informed choice for FP method users. SPs delineated that newly supplied IUDs, imported by the Government of Egypt, were not of adequate quality compared with those were supplied by USAID.

\section{The multiple competing MOHP programs} reducing support to FP service

There was marked reduction in the role of $\mathrm{CWs}$ due to involvement in different health activities in addition to FP. Provision of FP as free service compared to other Family Health Model facilities, reduced motivations of doctors and nurses to give priority to FP clients.
OCs use is matched with requirements of women for self-control method

FGD participants affirmed that women became highly oriented about different FP methods regarding use, side effects, needs for gynecological examination and follow-up. Consequently, women build up their decision for using OCs based on the fact that the use of OCs satisfies women's autonomy in selecting and using the method. OCs use satisfies the concept of "independence" of use and the use at any time and for any period. Other methods as IUD need both gynecological examination and follow-up and management of side effects as bleeding. injectables need the nurse for three-monthly injection. Condom use needs cooperative husband. implanon insertion needs trained qualified physician for implanon insertion and removal, as well as implanon is not available all the time in MOHP/outlets.

\section{Over dispersion of OCs in MOHP facilities is} due to shift toward OCs use

Among participants' responses, there were debates to the issue of leakage of OCs from MOHP FP-Clinics to other outlets. The FP directors and nurse supervisors attributed the increased requirements to increase supply of Microcept to the shortage of availability of Microcept in private pharmacies. Consequently, private pharmacy clients had shifted toward MOHP clinics to get Microcept which is usually available in MOHP/FP clinics. However, MOHP/HQ staff ascertained that Microcept is distributed to private pharmacies, and no shortage in Microcept supply to pharmacies. Therefore, the causes of shift toward OCs use could be due to changes in the pattern of service delivery in MOHP/FP clinics that motivate women to use OCs, and/or invisible leakage of OCs through

Table 9: Acceptability score for requirements for eligibility of nurses to provide IUD insertion services as expressed by the respondents by current job

\begin{tabular}{|c|c|c|c|c|c|c|c|c|}
\hline \multirow[t]{2}{*}{ Requirements to accept nurses for IUD insertion } & \multirow[t]{2}{*}{ Acceptability } & \multicolumn{7}{|c|}{ Current job of the respondents } \\
\hline & & FPDD & FPDNS & Male physician & Female physician & FP nurse & Total & $\mathrm{p}$ \\
\hline \multirow[t]{2}{*}{ Training of nurses in age of $18-35$} & Acceptability score & $38 \%$ & $46 \%$ & $43 \%$ & $39 \%$ & $47 \%$ & $44 \%$ & 0.7 \\
\hline & Total respondents & 43 & 49 & 43 & 77 & 150 & 362 & \\
\hline \multirow[t]{2}{*}{ Training of nurses in any age group } & Acceptability score & $21 \%$ & $33 \%$ & $38 \%$ & $24 \%$ & $37 \%$ & $32 \%$ & 0.1 \\
\hline & Total respondents & 38 & 47 & 41 & 79 & 141 & 346 & \\
\hline \multirow[t]{2}{*}{ Training of nurses worked in FP for more than 5 years } & Acceptability score & $46 \%$ & $61 \%$ & $63 \%$ & $50 \%$ & $65 \%$ & $59 \%$ & 0.03 \\
\hline & Total respondents & 40 & 47 & 40 & 82 & 146 & 355 & \\
\hline \multirow[t]{2}{*}{ Have Specialized nurse for IUD insertion } & Acceptability score & $28 \%$ & $38 \%$ & $32 \%$ & $39 \%$ & $44 \%$ & $39 \%$ & 0.07 \\
\hline & Total respondents & 38 & 49 & 38 & 72 & 140 & 337 & \\
\hline
\end{tabular}


over- recording of OCs use as dispensed Microcept to clients rather than true users of the method. Thus, auditing at the clinic level that includes review of the clients' form and the amount of dispensed method could investigate the leakage process. If it is there, it is the issue of logistic management cycle for contraceptive commodities.

\section{for IUD use \\ Revising the contraceptive technology issues}

The FGD participants went through brainstorming activity to deal with the issue of shift from IUD to OCs use. Raised issues were related to contraceptive technology of IUD and dynamics of use. After declaration of the WHO that IUD could be inserted and to remain in the uterus for ten years and more, women do not have to shift to another method. Therefore, IUD users become continuing users without contacting the FP clinic for follow-up. However, OCs users/continuers carry on visiting FP clinics to get the method on-monthly basis and recorded as return visit users for OCs. The issue related to new young female generations who added new cohorts of women in the child bearing period raises many inquiries about the pattern of contraceptive use. The new FP users could be interested to use OCs rather than IUD for different personal and fertility reasons or they did not find SPs to guide them for informed choice to other long-term method as IUD.

The incentives and training policies have major role for shifting from IUD to OCs

FGD participants focused on two important disputes; the incentives and the training systems. Incentives to physicians to provide the IUD insertion services are pivotal issues. The physicians are looking for training that fulfill the quality standards, and build the trustable skills in IUD insertion. The attentiveness toward good training and acquiring skills in IUD insertion delineates that those skills are essential to be practiced in public sector to get experience and to provide this service in private clinics with good quality to keep good reputation. However, the current training in FP is not enough to satisfy the needs of physicians. In addition, the high turnover, and thinking about the professional career had made thinking about capacity building in FP become no more appreciated.

Nurses could provide IUD insertion services, but legislations outlaw this policy

The participants from MOHP/HQ and FP nurse supervisors had demonstrated interest to build the capacity of nurses to provide IUD insertion services. They claimed that nurses are currently included in the midwifery training program which is more difficult and risky practice than IUD insertion. In addition, in some of the FP clinics, the nurse - behind the seen successfully provides the IUD insertion service compared with nontrained physician.

However, some participants raised the issue that the nursing legislation forbids the task of IUD insertion to be within the job description items of FP nurse. However, testing this intervention is needed before advocacy for making nurses perform the task of IUD insertion.

\section{Discussion}

The study described the situation of FP program in Egypt throughout the historical period of foreign donations to FPP that ended in 2005 and the current situation of self-reliance on the governmental policies and resources to operate FP program. The issues raised by this study are crucial to policy makers and FP program managers. Egypt goals of reducing fertility rate based on FP program had the challenges related to health system-contraceptive security, management manpower resources, cultural/women factors, and contraceptive technology. Those challenges formulate the determinants and dynamics related to method mix across time and geographical areas of Egypt [19], [20]. The notion that raised the need to conduct the current study was raised first by the National Population Council [21] where the Annual statistical Reports published the fact that the CCR for the dispensed FP methods at national level showed marked decrease from $56 \%$ (2002) to $53 \%$ in 2007 [21]. The percent contribution of Governmental, Private and NGOs in CCR showed changes from $79 \%, 15 \%, 6 \%$ (2002) to be $82 \%$, $12 \%, 5 \%$ (2007) for the three sectors, respectively. The percent contribution of IUD to national CCR was $73 \%$ in 2003 and reach to $69 \%$ in 2007 , versus $12 \%$ and $16 \%$ for OCs for the same years [7]. The changes in method mix in CCR were reflected on information published by EDHS 2005-2014. EDHS 2005 showed that CPR was $56.5 \%$ with method mix: OCs $16.7 \%$, IUD $61.5 \%$ and injectables $11.9 \%$. In EDHS 2014 CPR was 56.9\% (OC $27.4 \%$, IUD $51.4 \%$ and injectables $14.5 \%$ ) [5], [6], [17]. Therefore, service statistics predicted those changes as presented at community level in EDHS [7]. Such findings indicate the importance of health services research that consider output data/service statistic guides for the need for operations research to answer specific managerial problem that explain the changes in pattern of FP method use [22], [23], [24].

The study design involved FP managers at central, governorate, district and SPs in FP clinic, with participation through self-administered questionnaires, in-depth interview, and FGDs. This approach was crucial to go in-depth into very critical determinant issues related 
to the health system, contraceptive technology and cultural background that influence shift from IUD to OC use [25], [26]. The study could provide specific roles in FP services delivery. Physicians play the dominant role in formulating the profile of method mix. Well-trained physicians and incentives for IUD insertion services could influence FP counseling process to build clients' positive attitude toward IUD use [27]. On the other hand, current situation is characterized by shortage in number physicians, ineffective training, and stopping incentive system after phasing out of foreign donation. Consequently, the decisionmaking for selecting the FP method is left to clients who formulate specific criteria -outside the scientific concepts of contraceptive technology. Clients evaluate the method from specific aspects, as autonomy, independent of SPs, availability all the time in Primary Health Care facilities and at low price, and do not need gynecological examination [28]. OCs use according to those criteria become the method of choice for women at any age, with any morbidity (that contradict use of hormonal contraceptives), and lactation status [29]. The problem of availability of physicians had been tried in service deprived areas through mobile clinics where Gynecologist and FP specialist could provide IUD insertion process. However, the cost efficiency was high if compared with services in fixed clinics [30].

The study raised important sensitive issues related to leakage of OCs from MOHP clinics to other outlets. In addition, it provided thinking about the policy of involvement of nurses in IUD insertion. Contraceptive technology has to work on safer IUD with less side effects [31].

\section{Strengths of the study}

The current study builds the evidence-based information about shift from IUD use to OCs from survey studies as EDHS 2008 and 2014. Supporting of this view was also from policy makers and FP programs planners and services providers. The foreign donations for supported FP program that depend on long-acting, safe and effective method as IUD and motivating doctors through quality training and supervision and incentive. Phasing out of donor support, and self-dependency on OCs manufactured in the country could answer the research question. The study adds a new dimension for IUD regarding the technology regarding methods of insertion, side effects, and follow-up for scaling up its use as effective long acting FP method. The major strength of the study is related to the methodology. The study used both quantitative and qualitative data. The study worked on four level of FP-service delivery system: Central, governmental, district and FP SPs levels. Therefore, the study included multiple sources of data and information.

\section{Limitations of the study}

The study did not included FP clients who shifted from IUD to OCs. This needs specific study with large sample size to get appropriate information as this issue is multifactorial as it will include different individual issues rather than health system issues. The results of the study could not be generalized as it is a health system research, and results are specific to a certain communities, in which UNFPA-CSP is working. However, the methodology of the study could be generalized.

\section{Conclusion}

The three articulating issues that lead to shift from IUD to OCs: Unsatisfactory training and incentive systems for SPs and the clients' choice of OCs for independent use/autonomy without need of provider's services and availability of OCs at reasonable cost in the public sector all times. MOHP-CSP.

The study was part of consultancy activities for

\section{Acknowledgments} participants

All researchers are thankful to all study

\section{References}

1. World Health Organization. World Health Statistics 2016 Monitoring Health for the SDGs, Sustainable Development Goals. Geneva: World Health Organization; 2016.

2. Lince-Deroche N, Pleaner M, Morroni C, Mullick S, Firnhaber C Harries J, et al. Achieving universal access to sexual and reproductive health services: The potential and pitfalls for contraceptive services in South Africa. S Afr Health Rev. 2016;2016(1):95-108.

3. Hoton R, Peterson HB. The rebirth of family planning. Lancet 2012;380:77-9

4. Laila R. Reproductive Health Practices in Rural Bangladesh: State, Gender and Ethnicity. Rotterdam: Erasmus University Rotterdam; 2016.

5. Nahla AT, Debra R. The relevance of client-centered communication to family planning settings in developing countries: Lessons from the Egyptian experience. Soc Sci Med 2002;54(9):1357-68. http://doi.org/10.1016/ s0277-9536(01)00101-0 PMid:12058852

6. Ministry of Health and Population. Egypt Demographic and Health Survey. Egypt: Ministry of Health and Population, El Zanaty and Associates, and ICF International, 2014; 2015.

7. El-Zanaty F, Way A. Egypt Demographic and Health Survey 2005. Final Report. Cairo, Egypt, Ministry of Health and 
Population, National Population Council, El-Zanaty and Associates and ORC Macro; 2006.

8. MOHP/PS Services Statistics (2007-2011); 2015.

9. Barden-O'Fallon J, Speizer IS, Calhoun LM, Corroon M. Women's contraceptive discontinuation and switching behavior in urban Senegal, 2010-2015. BMC Womens Health. 2018;18(1):35. https://doi.org/10.1186/s12905-018-0529-9 PMid:29402320

10. Tin KN, Maung TM, Win T. Factors that affect the discontinuation of family planning methods in Myanmar: Analysis of the 2015-16 Myanmar demographic and health survey. Contracept Reprod Med. 2020;5:20. https://doi.org/10.1186/s40834-020-00126-5

11. Stoddard A, McNicholas C, Peipert JF. Efficacy and safety of long-acting reversible contraception. 2011;71(8):969-80. https:// doi.org/10.2165/11591290-000000000-00000

12. Nelson AL, Massoudi N. New developments in intrauterine device use: Focus on the US. Open Access J Contracept. 2016;7:127-41. https://doi.org/10.2147/OAJC.S85755 PMid:29386944

13. Samson ME. Progesterone-Only Oral Contraceptive Pill, Breast Cancer, Heart Disease, and Stroke. (Doctoral Dissertation); 2016. Available from: https://scholarcommons.sc.edu/etd/3596. [Last accessed on 2021 Jan 21].

14. Polis CB, Bradley SE, Bankole A, Onda T, Croft T, Singh S. Contraceptive Failure Rates in the Developing World: An Analysis of Demo- graphic and Health Survey Data in 43 Countries. New York: Guttmacher Institute; 2016. Available from: http://www.guttmacher.org/report/contraceptive-failurerates-in-developing-world. [Last accessed on $2021 \mathrm{Apr}$ 15].

15. Eshun P. Factors affecting maternal health care delivery in the Komenda Edina Eguafo Abrem municipality of the central region. University of Ghana; 2015. Available from: http:// ugspace.ug.edu.gh. [Last accessed on 2021 May 01].

16. Nicholas SA, Samuel K. Assessment of the effects of the free maternal health policy on maternal health: A case study of new Juaben Municipality, Koforidua, Ghana. Int J Bus Soc Res. 2016;6(7):51-62. http://dx.doi.org/10.18533/ijbsr.v6i7.292

17. Modi GA, Chaudhary B. Public Healthcare Delivery System: Contemporary HR Policies and Success. Vol. 5. Pacific Business Review International; 2012.

18. El-Zanaty and Associates. Study on Reproductive Health Impact of Family Health Model Pilots in Egypt. MOHP and UNFPA Center Agency for Public Mobilization and Statistics (2007-2011). Egypt: Statistics Year Books; 2008.

19. Abdel-Razik MS, Abdel-Hai R, Ibrahim H. Study the causes of reduction in CCR for dispensed FP methods in Egypt 2002-2007; 2008.

20. King TL, Brucker MC, Kriebs JM, Fahey JO. Varney's Midwifery. Burlington, Massachusetts: Jones and Bartlett Publishers; 2013.
21. GBD 2017 SDG Collaborators. Measuring progress from 1990 to 2017 and projecting attainment to 2030 of the health-related sustainable development goals for 195 countries and territories: A systematic analysis for the global burden of disease study. Lancet (London, England). 2018;392(10159):2091-138. http:// doi.org/10.1016/S0140-6736(18)32281-5

22. National Population Council (NPC). Annual Statistical Report (2002,2003,2004,2005,2006, 2007, 2008, 2009, 2010, 2011). Ghana.

23. Wainwright DW, Oates BJ, Edwards HM, Childs S. Evidencebased information systems: A new perspective and a road map for research-informed practice. J Assoc Inf Syst. 2018;19(11):1035-63.

24. Loewenson R, Mamdani M, Todd G, Kadowa I, Nswilla A, Kisanga $\mathrm{O}$, et al. The Role of an Essential Health Benefit in Health Systems in East and Southern Africa: Learning from regional research. EQUINET Discussion Paper 113, TARSC and IHI, EQUINET, Harare; 2018. Available from: http://www. equinetafrica. [Last accessed on 2021 Mar 15]

25. Harron K, McGrath-Lone L, Mason S, Gilbert R. Using Linked Administrative Data for Monitoring and Evaluating the Family Nurse Partnership in England: A Scoping Report; 2016.

26. Ngeh IR. Assessing the Factors Influencing Utilization of Family Planning Services at the Community-based Health Planning Services (CHPS) in the Bongo District of the Upper East Region of Ghana (Doctoral Dissertation); 2017.

27. Dumbura T. Socio-cultural Factors Influencing Choice of Family Planning Methods among Rural Women: A Case Study of Ward 10 of Sanyati District (Doctoral Dissertation); 2015

28. Satia J, Chauhan K. Review of Research Studies. In: Improving Quality of Care in Family Planning. Singapore: Springer; 2018. p. 75-104.

29. Kumar J. How Does Quality of Care Relate to a Rights-Based Approach to Family Planning Programs. New York: Population Council; 2015.

30. O'Brien E. Long-acting Reversible Contraceptives in Vermont: A Survey Based Assessment of Current Knowledge of Providers of Women of Reproductive Age. Graduate College Dissertations and Theses; 2016.

31. Nall M, O'Connor S, Hopper T, Peterson H, Mahajan B. Community women and reproductive autonomy: Building an infrastructure for long-acting reversible contraception (LARC) services in a mobile health clinic. J Health Care Poor Underserved, 2019;30(1):47-58. http://doi.org/10.1353/ hpu.2019.0006 PMid:30827968

32. Bhadra B, Burman SK, Purandare CN, Divakar H, Sequeira T, Bhardwaj $A$. The impact of using nurses to perform postpartum intrauterine device insertions in Kalyani Hospital, India. Int $\mathrm{J}$ Gynecol Obst. 2018;143(Suppl 1):33-7. 